\title{
The Strategy of Innovative Development of Cross-Border E-Commerce Platforms in Vietnam
}

\author{
Dao Duy Tung ${ }^{1}$, and Huynh Thi Ngoc Ly² \\ ${ }^{1}$ Siam University, 10160, Bangkok, Thailand \\ ${ }^{2}$ Institute for Development and Research in Banking Technology, VNUHCM, 700000 Vietnam \\ howiedtungdao. net \\ lyhtn@uel.edu.vn
}

\begin{abstract}
Over the past few years, Vietnam has been on the path of developing Cross Border Electronic Commerce (CBEC). E-business platform enterprise growth is scalabling transactions. CBEC's economic effects are observed under four aspects as (1) Resource aggregate effect: cost effi-ciency, trading between producers and consumers is realized by E-business platforms; (2) Net-work effect: the positive correlation of platforms' product or services with the quantity of con-sumers in increasing; (3) Innovation effect: startup costs for innovation (promotions, business models, new-coming products and services) have been recovered with E-business platforms. (4) The value of brand effect.
\end{abstract}

Keywords: cross-border e-business platform, network affect, innovation effect, Vietnam, multi-side platform.

\section{$1 \quad$ Introduction}

Cross border electronic commerce (CBEC) is transactions via platforms among trading parties from different customs frontiers, third-party payment as settlement for trade; delivery of goods via cross border logistics and tracking; collection; warehousing and application of big data formed in the transaction process. Current studies mostly focus on the status quo and development tendency, strength and weaknesses, logistics and payment systems. These studies elaborate the economic effects of CBEC platform based on the theory of economics and analyze innovative development to enrich the theoretical research. CBEC origi-nated in market demand, and its development has benefited towards supporting policies and measures. It has become a new industry of international trade, in which CBEC provides a new driving force for the growth of Vietnam's foreign trade. It is a positive correlation to promoting the liberalization and facilitation of international trade and innovation of the industry, changing the mode and enhancing the comprehensive competitiveness of foreign trade. CBEC breaks the timing and geographic boundaries; expands trading channels; min-imizes transaction costs and fully promotes trade. In this study, the author puts forward suggestions for the innovative development of the platforms through analyzing the economic effects. 


\section{Theoretical Background}

\subsection{The connotation of the platforms}

In economics, when two or more users are connected to be able to perform simply and exchange or a transaction by a platform, it is considered as "double sided" or "multifaceted". Users are diverse as buyers and sellers, advertisers, software developers, social media users, etc. Online platforms reduce digital information cost that normally exists in offline markets; therefore, all users acquire economic benefits (Martens, 2016). There is trending wave changing consumers' behaviors selling not only in traditional but also in online channel. Thanks to successful platforms designing network effects that users in different marketplace are attracted by. To improve their positions, platforms uses data collection from users' behavior. Two-sided markets are defined as markets involving "two groups of agents who inter-act via 'platforms,' where one group's benefit from joining a platform depends on the size of the other group that joins the platform." (Armstrong, 2006). There are two features of each platform according to Hagiu and Wright (2011) "(a) they are enabled direct interactions between two or more distinct sides and (b) each side is affiliated with the platform. Direct interaction means two or more distinct sides retain control over the key terms of the interaction, as opposed to the intermediary taking control of those terms. In the situation, the interaction involves trading then the key terms of the interaction could be the pricing, bundling, marketing and delivery of goods or services, the ability to determine the nature and quality of services offered, the terms and conditions, etc. Affiliation is defined as users on each side consciously carry out platform-specific investments that are necessary in order to interact directly each other. The investment could be a fixed access fee (e.g., buying a video game console), expenditure of resources (e.g., spending time and money on learning to develop applications using the iPhone's APIs), or an opportunity cost (e.g., driving to a shopping mall, joining a loyalty program)." Thus, multiple sides are necessary for the platform to create cross-group network effects by affiliation. Multiple sides of the platform trade result in complementary value, and interact through the platform, thereby creating more values. Users of the platform rely on each other to realize plat-form value creation, which is the most important feature of platforms. Therefore, when rules of platform development are enacted, interdependence between buyers and sellers should be considered. Differentiated rules according to the characteristics and requirements of various platform users must be set up. The degree of dependency among users is not sim-ilar. Platforms tend to attract users by charging less or even zero fee while the other side of the platform needs a large user base, so the free service on one side will be compensated by returns from the other side. A typical example is the instant messaging software as Zalo, Line or Telegram. In addition to providing free instant messaging services, they provide a variety of professional services such as news, community, financing, payment, gaming, e-commerce, and online car-hailing service. Moreover, Zalo and Facebook also provide basic instant messaging services to attract a large user base whose huge demand has become a driving force end of the platform to access to the developer or other contents which bring about the high value (eMarketer, 2016; Tyagi, 2018). 

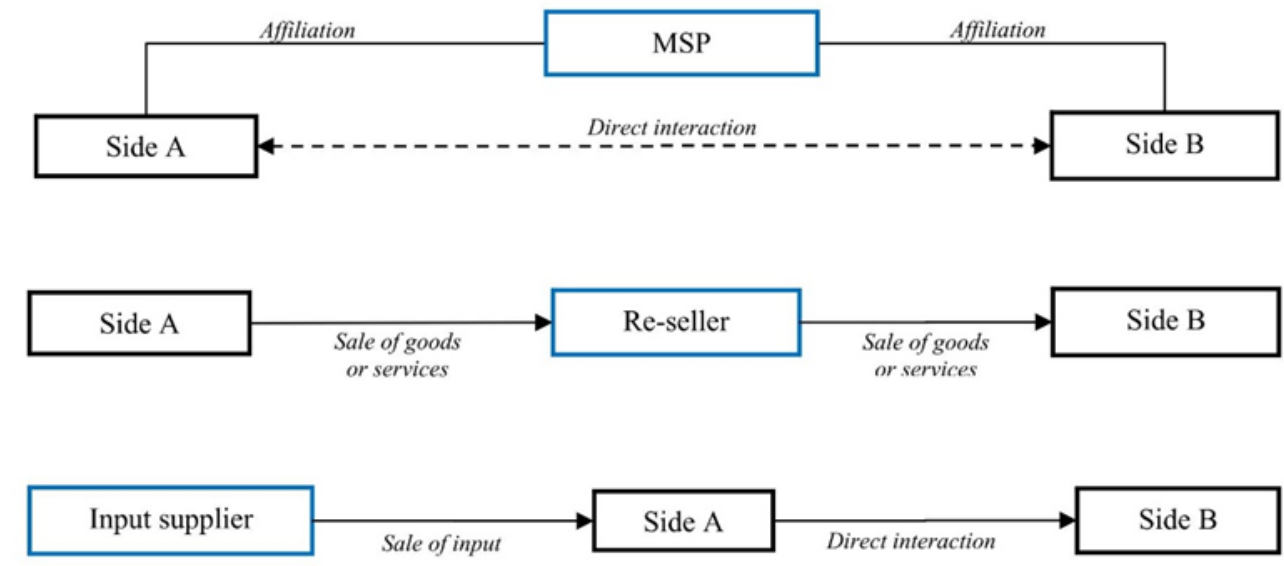

Fig. 1. Differences between input suppliers, MSPs and re-sellers (Hagiu \& Wright, 2011, p. 16)

\subsection{The network effect and network externality of multi-sided platforms}

If the value of a product or service surges the same number of users, it is judged to have a network effect (if it is viewed as a bilateral market). Furthermore, it is linked to the users of advertisers on the other side. The more users who use search engines, the more dependent the other side of the search engines is. The platform has the potential to induce additional ad revenue from advertisers. Network outwardness is an incomplete internal network effect. The network effect is split into direct network effect and indirect network effect. Firstly, the direct network effect identifies the worth of a product or service that will increase according to the rise the variety of customers. Therefore, the direct correlation effect between indirect and direct networks is established. For example, a fixed type of smartphone as long as users use matching origin charger then their smartphone increases durable and reduce trouble. That is the reason why the number of users using the charger increases. The charger has an addition for smartphones and resulted in the increase of us-ers. A buyer's monopsony will form if the indirect network effect is internalized. For tradi-tional independent industries, it is normally assumed that demand depends on the price of a product or replacement products. For a multi-sided platform, the demand for a product on one facet also depends on the quantity of products on both sides of the platform. In needed, A is willing to complement for B and reverse. The analysis of the multi-sided platform cannot ignore the mutuality among the platforms.

\subsection{Features of Multi-sided Platforms}

Basically, the multi-sided platform is a pricing motive. Multi-sided platforms can create value for multiple customer groups. The relative price charged on both sides of the 
platform should be in line with the demand, and the optimal price from the standpoint of a maximum bottom line or social benefit is lower than the marginal cost on the platform side and higher than the marginal expense on the other side of the platform. Changes in platform style affect to the demands of the complete platform. To illustrate, we tend to presume a platform creating a style that lowers the general transaction value such as substantiating the finger-print identification technology for shopping. The modification in style improves the poten-cy of the complete platform, improves consumers' welfare by increasing user expertise, enhance market output through a lot of purchasing. Consumer welfare veils on the con-glomeration result of every aspect of the platform. Therefore, the advantages and costs of product style changes are passed to the complete platform. Style changes could have positive effects, and they additionally cause negative effects. Positive effects could also be profits, and negative effects could also be costs. Profit and cost are going to be arisen by the whole platform.

\section{An Analysis of the Economic Effects}

\subsection{Resource Aggregate Effect}

In the internet era, data transmits at a particular quick speed and the economy and society are extremely integrated, which greatly reduces the transaction cost and the resource allocation cost. These vital changes lead to intensive reorganization and aggregation of resources (Chung \& Fitanides, 2016). The platform realizes the resource aggregation within the demand facet, to quickly assemble massive numbers of users. Innovative business models refer to social software, search sites. As a result, information push is quickly rising on the platform and appliances and extensively applied. The radical functions of the new service are often used free of charge to collect an enormous range of users during a short period of time with positive feedback. Consequently, platform firms accomplish the aggre-gate of market resources. CBEC platform collects colossal data on the transaction of a differentiated product, services, and generate their info aggregation result. Producers and spenders depend on the platform for direct trading and optimal reducing transaction costs. Moreover, relevant industrial chains are extended to support the platform, promote the event of connected industries and manufacture radiation effects. With reliance on various market platforms, firms will separate from the constraints of size and geographical position and provide merchandise and services to customers around globally.

\subsection{Innovation Effect}

CBEC innovates business models, selling merchandise and services based on platforms. To compensate for start-up cost, up-to-date products and services are offered to customers via transactions conducted by platforms (that is usually fixed during innovation period in order to encourage innovating activities from companies). Technological innovation is proved by providing the latest products or services due to creation is adopted to producing and providing fixing. The incremental profit of technology innovation is principally embodied within the start-up value and innovation method. The 
start-up cost could be a fixed charge and that does not amend with the modification of production. At the same time, the start-up cost could be an unsuccessful price. Once the business call is taken, it cannot be modified by present or future decision. If innovation is achieved, the spins-off cost is compensated by the sale of merchandise or service. Industries with intense fewer natural resources depend on less material inputs in product or services provision. The price of extra inputs within the production method is also neglected compared to start-up prices. The tremendous scale of a web platform will spread the big start-up cost and cut back the common value of products or services. Thus, the companies get the revenue raising, which stimulates innovation activities of firms. The products or services fashioned by technological innovation are offered to customers through the transaction of CBEC platforms.

\subsection{Brand Equity Effect}

Effect of brand equity refers to the firms owning whole accomplished brand design, marketing, and maintenance. The combination of all factors leads to brand enhancement; however, brand growth arises new competitors. Thus, identical products can be sold at different prices. Similar merchandise of notable brands and customary brands always exist a giant gap in price. The differentiated worth is shown within the brand, and advertisements work on brand promotion (Huyen, 2017). Therefore, innovation is that the elementary supply of differentiated worth. CBEC platform creates opportunities for firms to accomplish brand selling and precision selling through the platform, overseas customers will directly obtain information on commodities and user analysis of domestic firms, thereby provide a comprehensive method of raising the whole awareness of domestic firms. The company will use a large amount of customer information data to analyze potential markets and international markets based on consumers' preferences. Consequently, it generates a speedy response towards changes in demand, influencing on brand style, promoting and maintenance to maximize the implementation of precision selling. Thus, increase the value of a brand, and meet demands of global customers.

\section{Development Status}

\subsection{Rapid Growth of Transaction Scale}

In current years, with the speedy development of economic globalization and information technology, the dimensions of transactions in Vietnam has witnessed a continual sudden growth. CBEC has become the foremost active part of Vietnam's foreign trade. EU-Vietnam Business Network (2018) released a report 2015, the size of B2B transactions reached $22.9 \%$ of the whole turn-over, which occupies an absolute advantage. Meanwhile, B2C has quickly grown, accounting for $20 \%$ of total turnover in 2017. Moreover, the structure of CBEC transactions in Vietnam has been adjusted, and the import and $\mathrm{B} 2 \mathrm{C}$ mode have enhanced their proportion within the transactions. Vietnam's CBEC is an export-oriented pattern. 


\subsection{A supplement to general trade}

The quick increase of CBEC is ever-changing consumers' disbursement habits because of the advantage is principally embodied in higher cost performance of products and searching convenience following the increase of the shopper demand. That is why the quality of private commodity increased around the world. Industrial upgrading and restructuring, as a replacement variety of trade forms an efficient supplement to the one channel of general trade and satisfies consumers' distributed demand. The entire country's recognition has gradually increased, and the fragmented cross-border trade has been incorporated into the regulative system to create feasibility.

\subsection{High-speed and steady development of CBEC platforms}

During recent years, CBEC has witnessed a speedy development an oversized range of plat-form firms by enhancing users' expertise within the fierce competition and promoted the steady growth transaction scale. CBEC platforms are classified into subsequent types: B2B (business-to-business) as VietTrade, Vietnam Trade Fair, TradeFord and another platform with sturdy competitiveness; B2C (business-to-customer), stable pattern of platforms, for example, Lazada Vietnam, Tiki, FPT shop and Sendo in association with to FPT Corporation, and Adayroi. Third-party service firms, for instance, fado.vn, amabuy.vn and different platforms provide integrated foreign trade services, for example, third-party payment firms as Zalopay, Momo and PayPal, customs declaration, warehousing and supply firms includ-ing traditional services (ViettelPost, EMS, VNPost); start-up giaohangnhanh, supership, and giaohangtietkiem; international players (Grab Express, and Lazada Express), according to Vietnam Ministry of Planning and Investment.

\section{Discussion}

\subsection{The Carriers of the Platforms Need Improving}

The development of the CBEC involves the expansion of its carrier and the improvement of the infrastructure. As a significant platform carrier for the development, the construction of a comprehensive pilot area must draw on the advanced expertise and practices, explore the business process, technical standards and modes of direction to perpetuate the consistent and promotable expertise. New business patterns are enforced to attract corporation conglomeration, increase employment and promote startup and innovation. Carriers as pub-lic service and startup together with innovation base ought to be improved. The functions of these platforms must be optimized.

\subsection{The Functions of the Platforms Need Optimizing}

The event mode of online and offline fusion must be more promoted. The changes within retailing trade are typically among the specialization of the participants and the division of functions. CBEC is marketing, thus it will additionally present the trend in 
specialization and division. Professional planners offer brand-building solutions. IT corporations develop e-business platforms and provide integrated solutions as data mining technology. Provision firms provide solutions as customs clearance and cargo transport. The specialization of the business depending on that system performs improvement of this platform for cultivating core competitiveness.

\subsection{The Development Modes of the Platform Need Innovation}

It is necessary to strengthen the development and deepen cultivation of overseas markets with innovative modes, and the ancient overseas warehouse model must be upgraded to satisfy the characteristics of overseas markets. At present, the target market of B2C in Vietnam concentrates on developed countries with complete infrastructure and a high ratio of online searching. In addition, the export scale in these countries is simple to extend and the markets would like deep cultivation. In recent time, the region Latin America is the fastest-growing region in worldwide, compared to Asia-Pacific, the Middle East, and African countries closely. The emerging markets would like to enhance online searching resources and openness in regulations. As a result, that increases consumers' buying power and the potential of the markets.

\subsection{The Brand Equity of the Platform Needs Promoting}

The future development trend of companies is to create quality and brands. Having prac-ticed the initial stage of developing the market with the low-price distribution of products, companies face intense competition in homogenized commodities with huge numbers double than companies gushing within the platforms. The gross margin of non-brand goods is sort of low, and the companies with own brands are supported energetically by the platforms. Hence, competitiveness of famous brands in some domestic platforms has been improved. Most of CBEC platforms attach additional importance to management system con-struction, product technology innovation, service quality promotion, market developing.

\section{$6 \quad$ Suggestions and Conclusion}

\subsection{Integrated Development of Offline Industrial Parks and Online Single-Windows}

Constructing an overall layout of the core area and a metropolitan area plus e-business cluster should be applied in a comprehensive pilot area. In the first stage, with the core area as a middle, companies registered in "single-window" platform to explore business model innovation. In the second stage, the expertise accrued within the core area is going to be unfolded to companies registered in "single-window" platform in major cities. The final stage is to make modes and standards, which is going to be unfolded to companies regis-tered in "single-window" platform in different cities in an exceeding region. Promoting industrial development, increasing exports and regulating imports 
should be targeted on. The model of B2B should be expanded among companies to strengthen new competitive-ness technology, brand, quality and service. The model of B2C should be used as a helpful add-on to B2B to support small and medium-sized enterprises to grow up. In the existing comprehensive pilot area, a variety of industrial parks with multiple specific functions are to be established to create the pattern of one area and multiple parks. Large-scale platform companies in numerous fields, such as B2B, B2C, comprehensive foreign trade service, customs declaration, reposition, logistics, third-party payment companies, and massive data operation should be a conglomerate within the industrial parks to determine a sound eco-logical system. Industrial chains are extended, and the industrial scale is enlarged by com-bining different industrial benefits of varied industrial parks. Cooperative development and benign competition of every e-commerce industrial park ought to be promoted. Taking full account of the characteristics from a cluster and ecological system of the platforms, com-panies will prepare affordable development directions to appreciate the coordinated devel-opment alpha and export. The operation of B2B, B2C and Online-to-Offline (O2O) business models are to be optimized. When experimentation and appraisal, innovative measures ought to be promoted in exceedingly broader scope to create the influence and driving force comprehensive pilot area. Multiple offline platforms should be established within industry parks to conglomerate e-commerce platform companies, integrated foreign trade service companies, ecommerce service corporations, e-commerce abilities, and different factors. Reliance on a scheme that the platforms will offer firms with services like customs clearance, intelligent provision, financial services, human resources and alternative one-stop integrated services to grant powerful support to an online "single-window" compre-hensive service platform, to push integration mutual support and coordinated development both online and offline.

\subsection{Optimization of Functions of Online Cross-Border E-Commerce Comprehensive Service Platforms}

Reproduce and promote support an online integrated service platform to optimize platform functions. Ho Chi Minh City is a pioneer launching an upgraded version and integrated online service based on big data that breaks the obstacles of customs, taxation, foreign exchange, logistics to realize data interconnection of regulative departments, financial estab-lishments. In addition, the large information platform brings along many innumerable ap-proved data including trade goods inspection, foreign exchange, taxation, and another dif-ferent department. In other words, data combination based on corporation registration, declaration, transaction, logistics, finance, commodities, and business credit create an enor-mous information hub. Through a standardized process, integrating and developing huge data, CBEC companies can acquire government service and market service via abundant data. As the result, generate excellent service platform covers the entire process of business entity registration and import \& export of e-commerce, providing services like customs clearance (commodity inspection), provision (warehousing, transportation, insurance, ports), finance (foreign exchange, confirmative and export tax rebate) and other services. When platforms are linked as import \& export service and customs, commodity inspection, e-commerce transactions, 
logistics, payment, and third-party platform system, the ecosystem will be born to support users on registration, declaration, exchanging data and other functions. Through the information application system, e-commerce companies will acquire info on grade appraisal and market risks alert, and they may confer with information analysis reports and acquire information services as online bookings of supplying and finance. The online integrated service platform includes data from government departments and those from company service and market service in one, which breaks two-way barriers of government and market. The integrated analyzed massive knowledge will feedback to regulative departments for optimizing government service thence to provide innovating service. The functions of the integrated service platform are going to be unceasingly optimized to appreciate its transformation from one info platform to a commercialism platform, with the functions extending to the overseas promotion of commodities, transaction support, online provision, online payment, aftersales service, a credit system and client dispute settlement and alternative integrated services. The use of an integrated service platform may foster native corporation cluster. The platform will build up integration foster of exist foreign trade firms by encouraging potential e-commerce companies to sign contracts with the service platform.

\subsection{Supporting an innovative mode development of a cross-border e- commerce platform}

As a new pattern of international trade, the innovative development trend of e-commerce is remodeling the quality and the specialized platform, boost the aggressiveness of companies, to determine efficient and convenient bridges between producers and customers, and promote participation in international trade such as service corporations, manufacturers, foreign trade corporations, SMEs and micro internet businesses. Kick upstairs complement of third-party platforms, the development of B2B, B2C, O2O, and other business models. E-commerce companies will be launching offline stores to impact nearer contact with customers via "online and offline" mode. That is why firms should be making better to maintain users. After that, it helps companies to open new market opportunities.

\subsection{Brand equity creation through cross-border e-commerce platforms}

CBEC corporations should strengthen their own brand creation and innovative marketing. They should take hold of multiple needs of target market consumers and create unique a brand connotation. Meanwhile, the corporations can access resources to optimize their own brand building and management by optimizing internal resource allocation, make in-depth overseas market surveys, understand the environment of overseas market competition brand merchandise face, and implement global brand marketing strategy (Phuong, 2017). Cross-border exporters can carry out the brand operation and customer operation directly to overseas consumers and raise awareness of Vietnam's high-quality supply chain to enhance competitive edge. The use of a proprietary vertical e-commerce platform for brand creation mainly focuses on the in-depth operation of an industry or segmented market and operating B2C or B2B of the commodity of the same 
type. E-commerce platforms conglomerate a large amount of information on sales and consumer feedback. The consumer demand can be grasped through sales volume and consumer evaluation feedback. After that, corporations can determine the main target markets and offer goods to the markets, improve R\&D. For the reason that brands aiming at the target markets, find out unique market positioning and strive to create new products with features. Additionally, companies carry out implement platform value mining, create brand value combine market innovation, scientific and technological innovation, and merge cultural factors. Consumers' taste for goods has upgraded to spiritual experience such as new, aesthetic, personalized goods with a unique taste. The growth of the "soft demand" has stimulated corporations' increased investment in creative ideas and design, research and development, marketing and promotion to enhance brand equity (Ly, 2018). Therefore, corporations utilize culture, intelligent technology, platform performing interactive functions, and other resources to promote, disseminate and use this information to find good-looking consumer groups. Consumers expand the scope of information dissemination in the process of publication and use of information. The increase in value of brand stems from enhancing consumer awareness and experience towards goods and services. For instance, Facebook and another internet platform provide new models of social interaction. Facebook can be viewed as a replacement for advertising with consumers' word-of-mouth. Corporations can help promote marketing and expand their influences. Essentially, social networking has brought to full play a technological advantage and won abroad market. Besides, main commodities can be combined with holidays and hot topics take aim to target consumers. Not only do users and other social networks encourage to use Zalo but also corporations are pushing to promote and expand their influence, raise brand awareness which gets turnover. In addition, companies use technical tools to develop marketing channel platform. For instance, Zalo or Facebook applications can be used to main entrance on the search, share public accounts or share to other channels. As facilitate direct contacts between businesses and customers and open online traffic switches for stores. Social advertising also launches a combination of online and offline "smart retailing" marketing solutions through making strategies, advertising, coupons, writing-off and other ways to get through the traditional closed-loop marketing and expand marketing channels.

Research shows that transforming social web traffic into the e-commerce flow to offer opportunities for businesses in seeking customers, thereby to reduce the cost of consumer acquisition. Social advertising as a core advertising business unit generates many label categories through an in-depth analysis of consumer data. Advertisers can use cross-screen orientation, group development, and intelligent bidding technology to implement connections and dialogues with customers through Facebook, Zalo, CocCoc browsers or third-party mobile applications to reach the ultimate marketing goals. As an example, virtual money is not only developed and integrated on the social network which reduces customer habit in cash payment but also attracts the attention of users to use cashless payment as Zalopay a third-party mobile payment app, thereby users acquire benefit from preferential information and to share information with their friends after payment. CBEC platform should implement differentiated development modes, combine its own advantages and overseas consumer preferences, and rely on global brand influence to establish an online global marketing network. Domestic corporations 
and corporations enable to form alliances to materialize a service system in aspects of supply, value, and resources to enhance reliance of overseas consumers on Vietnam's CBEC platforms.

\section{References}

1. Armstrong, M. (2006). Competition in two-sided markets. The RAND Journal of Economics, 37(3), 668-691.

2. Chung, S. Y., \& Fitanides, A. (2016). Vietnamese SMEs and the digital economy risks and opportunities. Business Alliance Workshop, Competition Commission Singapore. Handbook on e-commerce and competition in Asean.

3. eMarketer (2016). Mobile messaging users in Vietnam choose homegrown Zalo. Retrieved from https://www.emarketer.com/Article/Mobile-Messaging-Users-Vietnam-ChooseHomegrown-Zalo/1014151

4. EU-Vietnam Business Network (2018). E-commerce industry in Vietnam.

5. Hagiu, A., \& Wright, J. (2011). Multi-sided platforms. Havard Business School. 1-31

6. Huyen, N. T. T. (2017). E-commerce market developments in Vietnam and the opportunties for logistics investor. Retrieved from https://medium.com/@nguyenthithanhhuyen/e-commerce-market-developments-in-vietnam-and-the-opportunities-for-investor-p1f47aae6f0b81

7. Ly, P. (2018). 3 insights about Vietnam's e-commerce landscape last year. Retrieved from https://www.techinasia.com/talk/vietnam-ecommerce-facts-2017

8. Martens, B. (2016). An economic policy perspective on online platforms. doi: $10.2139 / \mathrm{ssrn} .2783656$

9. Ministry of Planning and Investment (2018). E-commerce expected to grow strongly in 2018. Retrieved from http://www.mpi.gov.vn/en/Pages/tinbai.aspx?idTin=39412\&idcm=92

10. Phuong, N. (2017). Analysis of retail market in Vietnam: Case Vingroup. International business and logistics.

11. Tyagi, D. (2018). Did you know Vietnam has a famous instant messaging service of its ownZalo. Retrieved from https://rapidleaks.com/technology/vietnam-instant-messaging-appzalo/ 